\title{
The Effects of Plasmodium Falciparum Parasitaemia on Liver Synthetic Fidelity and Oxidative Stress Markers
}

\author{
Mieebi Martin Wankasi, Alabrah Peter Waibode, and Eni-Yimini Solomon Agoro
}

\begin{abstract}
Malaria has for century's defiled eradication due to pathophysiological and environmental complexities. The study was aimed at revealing the effect of malaria parasitaemia on hepatic synthetic fidelity and oxidative stress markers individually and synergistically. A total of five hundred subjects constituted the sample size, out of which two hundred comprised the control and three hundred the test group with grades of parasitaemia. Serum aspartate aminotransferases (AST), alanine aminotransferase (ALT), iron, malonaldehyde and glutathione were analysed using WHO approved methods. The results obtained indicated a significant increase $(p<0.05)$ in AST, ALT, malonaldehyde, and glutathione levels in malaria infected subjects when compared to the control group respectively. The result further showed a significant decrease $(\mathbf{p}<0.01)$ in serum iron concentration in malaria infected groups when compared to the control. In conclusion, malaria infection has a significant impact on the hepatic synthetic capacity and oxidative indicators. It is suggested that these observed biochemical change should be considered when malaria infected individuals are treated and managed.
\end{abstract} iron.

Index Terms - Malaria, liver enzymes, oxidative markers,

\section{INTRODUCTION}

Malaria is caused by obligate intracellular parasites, which live in the host erythrocytes and remodel these cells to provide optimally for their own needs. It is a febrile illness caused by protozoon of the genus plasmodium, transmitted to human by bite of infected female anopheles' mosquito [1]. The World Health Organization reported that malaria; the deadly parasitic disease is responsible for about ninety nine percent of death in Africa [2]. It is a foremost public health concern in tropical and temperate areas as it is infests 300-500 million people and causes 1-3 million deaths annually. In Africa a child dies from malaria every 30 seconds [3]. One-fifth of infants' death in Africa is also caused by the scourged of malaria. In Nigeria, approximately 0.25 million death of children under the age of five is caused by malaria yearly [4].

The liver has a wide range of functions including detoxification, protein synthesis, production of biochemicals necessary for digestion, storing of glycogen and hormone production [5]. These functions are mostly enzymatic involving various classes of enzymes. A lot of the body's important biomolecules necessary for existence are products

Published on August 31, 2020.

Mieebi Martin Wankasi, Niger Delta University, Nigeria.

Alabrah Peter Waibode, Federal Medical Centre, Nigeria.

Eni-Yimini Solomon Agoro, Federal University Otuoke, Nigeria.

(corresponding e-mail: siragoro@yahoo.com) of enzymatic processes. Aminotransferases synthesis and activities are mostly domiciled in the liver with comprehensive functions and clinical implications. Iron is an important element synthetized in the liver and is used for both spontaneous and enzymatic processes in the biosynthesis of wide-range of biomolecules. Iron plays crucial roles in the cellular metabolism orchestrated by the liver [6]. Iron is a principal index for anaemia assessment and classification. Anaemia is a major symptom of malaria leading to morbidity or mortality. Iron deficiency and anaemia are significant co-morbidities of malaria especially in children.

The propagation or blunting of diseases processes have been shown to be perpetuated by the generation of free radicals. Free radicals ferocity is a measure of the concentration of anti-oxidants and free radicals itself. An elevated free radicals or decreased anti-oxidants are indicators of degeneration and/or lipid peroxidation. Hence, it is pointer to health and vitality.

Glutathione is capable of preventing damage to important cellular components caused by reactive oxygen species such as free radicals, peroxides, lipid peroxides, and heavy metals [7]. Malondialdehyde (MDA) is the organic compound with the nominal formula $\mathrm{CH}_{2}(\mathrm{CHO})_{2}$. A colorless liquid, malondialdehyde is a highly reactive compound that occurs as the enol [8]. It occurs naturally and is a marker for oxidative stress. The degree of lipid peroxidation can be estimated by the amount of malondialdehyde in tissues [9].

Liver enzymes are increased in malaria parasitemia, to a level dependent on the degree of parasitemia [10]. The invasion of the liver cells by malaria parasite can cause organ congestion, sinusoidal blockage and cellular inflammation [11]. When these happen, the parenchyma aminotransferases (AST and ALT) and membranous alkaline phosphatase and gamma glutamyl transpeptidase enzymes of the liver leak out and find their way into the circulation, leading to increased enzyme activities [12].

The pathophysiology leading to anaemia could be loss of blood or iron. In malaria, iron loss resulting from lysis of blood cells due to plasmodia escape could be the basis of anaemia. The liver maintains the synthetic balance of iron concentration. The distortion to the balance could also be a contributing factor to anaemia resulting from the assault on liver cells by the plasmodia.

Although oxidative stress may often be a secondary event, it does play an important role in furthering tissue injury in some diseases. Malaria infected red cells appear to be under oxidative stress, may be as a consequence of parasite metabolism. Malaria parasites can be killed invitro by systems generating ROS/RNS and by exposure to lipid 
peroxides or cytotoxic aldehydes derived for peroxides [13]. However, information on the impact of plasmodium parasitaemia on hepatic synthetic fidelity and oxidative stress markers appear to be scanty. Thus, this study was intended to determine the effect of plasmodium parasitaemia on the AST, ALT, iron, malondaldehyde and glutathione levels.

This study has the propensity of unravelling the critical role of the source of iron deficiency and antioxidants in manipulating therapeutic intervention.

\section{Methodology}

\section{A. Study Area}

This study was carried out in Yenagoa Local Area Government of Bayelsa State, Nigeria. Bayelsa State is located in the South-South Geopolitical Region of Nigeria at 455`29 North Latitude and 615`51 East Latitude [14].

\section{B. Study Population}

The sample size was determined using G-Power Software. A total of five hundred (500) subjects were recruited for the study. Two hundred (200) subjects constituted the control group (negative to plasmodium count), while the three hundred (300) subjects constituted the test group (positive to plasmodium count).

\section{Selection Criteria}

Subjects with malaria parasitaemia without any underlying disease were included in the study as test group. Non-infected subjects served as the control. Subjects with any form of chronic diseases were excluded from the study. Ethical approval of the study was obtained from the Federal Medical Centre Yenagoa, Bayelsa State. Similarly, individual consent was obtained from participating subjects.

\section{Sample Collection and Preparation}

Blood samples were collected from recruited subjects by standard venipuncture technique using a $5 \mathrm{ml}$ syringe. The samples were dispensed into plain containers for biochemical analysis. A film of whole blood was made for malaria parasite count determination.

\section{E. Laboratory Analysis}

Serum aspartate and alanine aminotransferases activities were estimated quantitatively using end-point enzymatic method as modified by Randox Laboratories United Kingdom (Randox kit lealet). Serum iron concentration was estimated using Nitro-PAPS method-Monoreagent Glutathione concentrations were analysed by the Habig's method, while malonaldehyde concentration by the thiobabituric method.

\section{F. Statistical Analysis}

Data were analyzed with Statistical Package for Social Sciences (SPSS) program (SPSS Inc., Chicago, IL, USA; Version 18-21) and Microsoft excel. Student t-test was used in comparing the means of the studied biochemical parameters between the control and test groups. The level of significance was considered at $95 \%$ and $99 \%$ of interval confidence respectively.

\section{RESULTS}

TABLE 1: DEMOGRAPHIC CHARACTERISTICS OF ENROLLED SUBJECTS

\begin{tabular}{lc}
\hline FEATURES & STATISTICS \\
\hline Total number of subjects & 500 \\
Age range & $18-65$ years \\
Female patients & 260 \\
Male patients & 240 \\
Control Group & 2000 \\
Test Group & 300 \\
\hline
\end{tabular}

TABLE 2: MEAN CONCENTRATIONS OF SERUM AMINOTRANSFERASE ACTIVITIES AND IRON CONCENTRATIONS IN GRADES OF PARASITAEMIA AMONGST STUDIED GROUPS

\begin{tabular}{cccc}
\multicolumn{4}{c}{ AMONGST STUDIED GROUPS } \\
\hline Parameter & $\begin{array}{c}\text { Control } \\
(\text { mean } \pm \text { SD })\end{array}$ & $\begin{array}{c}\text { Mild } \\
\text { Parasitaemia }(+) \\
(\text { mean } \pm \text { SD })\end{array}$ & $\begin{array}{c}\text { Moderate } \\
\text { Parasitaemia } \\
(++) \\
(\text { mean } \pm \text { SD) }\end{array}$ \\
\hline AST $(\mathrm{u} / \mathrm{l})$ & $15.89 \pm 5.09$ & $21.58 \pm 11.38$ & $21.44 \pm 14.44$ \\
$\mathrm{ALT}(\mathrm{u} / \mathrm{l})$ & $10.27 \pm 4.16$ & $14.50 \pm 15.84$ & $10.70 \pm 6.70$ \\
$\mathrm{Iron}(\mu \mathrm{mol} / \mathrm{l})$ & $27.89 \pm 11.25$ & $12.24 \pm 75.85$ & $18.48 \pm 11.83$
\end{tabular}

AST $=$ Aspartate aminotransferase.

ALT $=$ Alanine aminotransferase

TABLE 3: COMPARISON OF BIOCHEMICAL PARAMETERS IN CONTROL, AND MALARIA INFECTED MILD PARASITAEMIA

\begin{tabular}{ccccccc}
\hline Parameter & $\begin{array}{c}\text { Control } \\
(\text { mean } \pm \text { SD) }\end{array}$ & $\begin{array}{c}\text { Mild } \\
\text { Parasitaemia } \\
(+)\end{array}$ & $\begin{array}{c}\text { \% difference of } \\
\text { mean }\end{array}$ & $\begin{array}{c}\text { t- } \\
\text { value }\end{array}$ & P value \\
\hline $\mathrm{AST}(\mathrm{u} / \mathrm{l})$ & $15.89 \pm 5.09$ & $21.58 \pm 11.38$ & $\mathbf{4} 35.8$ & 2.53 & $\mathrm{P}<0.05^{*}$ \\
$\mathrm{ALT}(\mathrm{u} / \mathrm{l})$ & $10.27 \pm 4.16$ & $14.50 \pm 15.84$ & $\mathbf{4} 41.2$ & 2.88 & $\mathrm{P}<0.01^{*}$ \\
$\mathrm{Iron}(\mu \mathrm{mol} / \mathrm{l})$ & $27.89 \pm 11.25$ & $12.24 \pm 75.85$ & 56.1 & 1.07 & $\mathrm{P}>0.05$ \\
\hline
\end{tabular}

TABLE 4: COMPARISON OF BIOCHEMICAL PARAMETERS BETWEEN CONTROL, AND MALARIA INFECTED MODERATE PARASITAEMIA

\begin{tabular}{|c|c|c|c|c|c|}
\hline Parameter & $\begin{array}{c}\text { Control } \\
(\text { mean } \pm \text { SD) }\end{array}$ & $\begin{array}{c}\text { Moderate Parasitaemia } \\
(++) \\
(\text { mean } \pm \text { SD }) \\
\end{array}$ & $\begin{array}{c}\% \text { difference of } \\
\text { mean }\end{array}$ & t-value & P value \\
\hline $\operatorname{AST}(\mathrm{u} / \mathrm{l})$ & $15.89 \pm 5.09$ & $21.44 \pm 14.44$ & 34.9 & 1.74 & $\mathrm{P}>0.05$ \\
\hline $\operatorname{ALT}(\mathrm{u} / \mathrm{l})$ & $10.27 \pm 4.16$ & $10.70 \pm 6.70$ & 4.2 & 0.31 & $\mathrm{P}>0.05$ \\
\hline Iron $(\mu \mathrm{mol} / 1)$ & $27.89 \pm 11.25$ & $18.48 \pm 11.83$ & 33.7 & 2.95 & $\mathrm{P}<0.01^{*}$ \\
\hline
\end{tabular}


TABLE 5: COMPARISON OF BIOCHEMICAL PARAMETERS IN MALARIA INFECTED BLOOD SAMPLES OF MiLD AND MODERATE PARASITAEMIA

\begin{tabular}{cccccc}
\hline Parameter & $\begin{array}{c}\text { Mild Parasitaemia } \\
(+)(\text { mean } \pm \text { SD) }\end{array}$ & $\begin{array}{c}\text { Moderate } \\
\text { Parasitaemia } \\
(++)(\text { mean } \pm \text { SD })\end{array}$ & $\begin{array}{c}\text { \% difference } \\
\text { of mean }\end{array}$ & t-value & p value \\
\hline $\mathrm{AST}(\mathrm{u} / \mathrm{l})$ & $21.58 \pm 11.38$ & $21.44 \pm 14.44$ & $\mathbf{4} 0.65$ & 0.03 & $\mathrm{P}>0.05$ \\
$\mathrm{ALT}(\mathrm{u} / \mathrm{l})$ & $14.50 \pm 15.84$ & $10.70 \pm 6.70$ & $\mathbf{4} 26.21$ & 0.612 & $\mathrm{P}>0.05$ \\
$\mathrm{Iron}(\mu \mathrm{mol} / \mathrm{l})$ & $12.24 \pm 75.85$ & $18.48 \pm 11.83$ & $\mathbf{1} 50.98$ & 0.003 & $\mathrm{P}>0.05$ \\
\hline
\end{tabular}

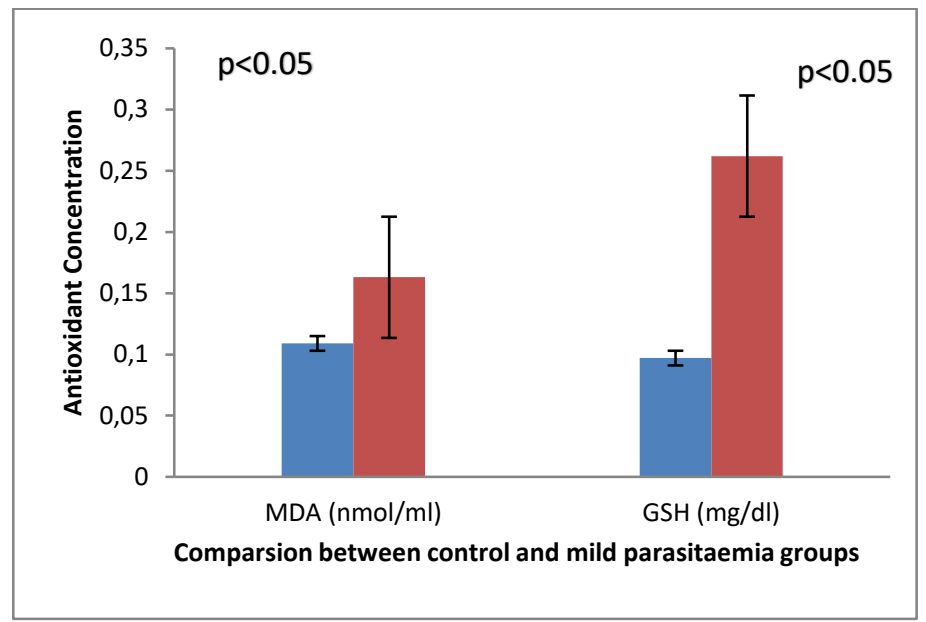

Fig. 1. Result of Malondialdyde and Glutathione control compared with mildparasitaema. MDA- Malonaldehyde

GSH- Glutathione

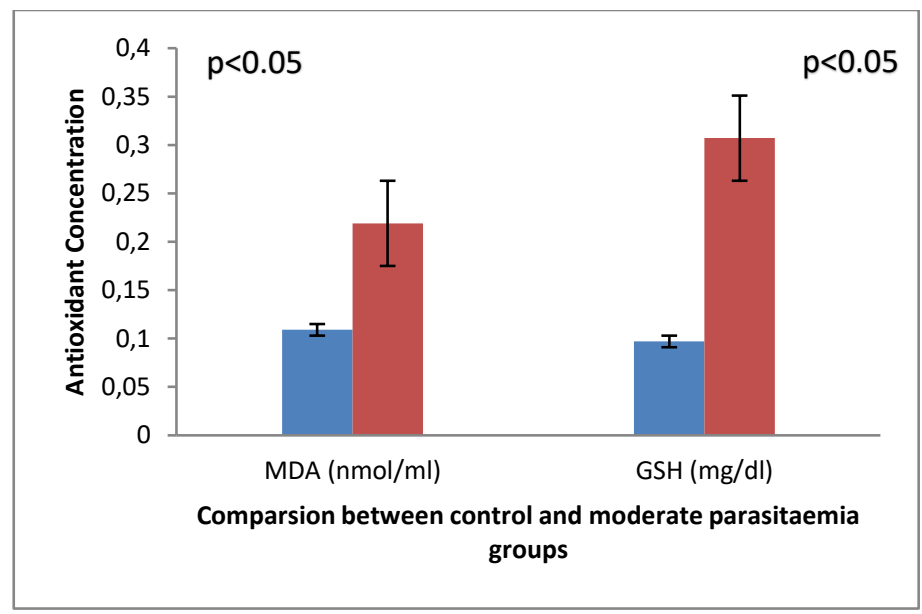

Fig. 2. Result of Malondialdyde and Glutathione control compared with Moderate parasitaemia.

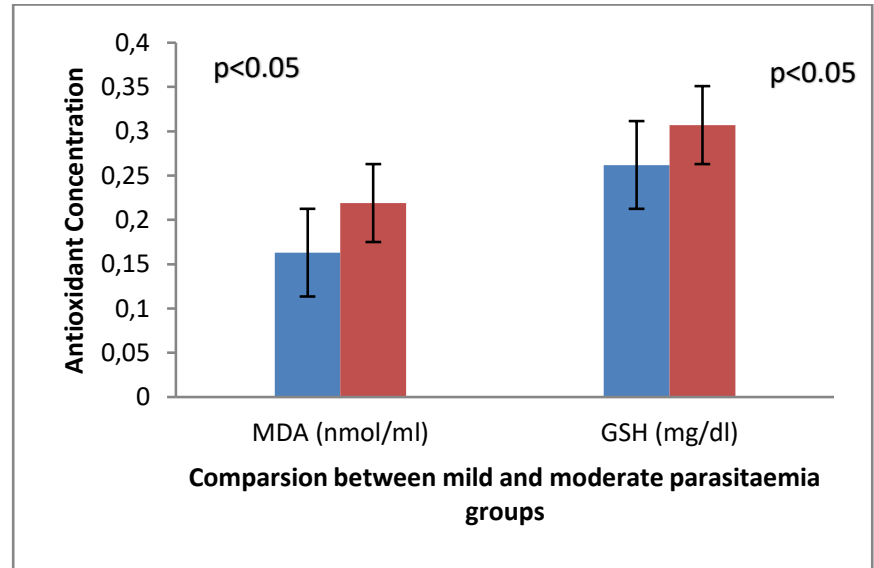

Fig. 3. Result of Malondialdhyde and Glutathione test group based on degrees of parasitemia. 


\section{DISCUSSION}

The results of the study showed a significant elevation of the serum aminotransferases and oxidative indicators (glutathione and malonaldehyde) in the test groups when compared with the control (Table 2 and 3). Whereas serum iron concentration showed a significant decrease comparatively in terms of control and test groups (Table 2 and 3).

The increase in enzyme activities could be attributed to assaults on liver parenchymal cells by the malaria parasites leading to the leakage of the liver enzymes into the general circulation. This finding is in agreement with the study carried out by Enemchukwu et al. [5] who reported that patients with untreated malaria parasite have high levels of ALT, AST and ALP in their blood. The finding also correlated with findings of previous studies of Mosab et al. [15]. and Guthrow et al. [16].

The study also showed a significant decrease in serum iron concentration in the test subjects when compared to that of the control. This could be associated with lysis of red cells and its utilization by malaria parasites for metabolic processes. Iron is utilized by malaria parasite for pyrimidine and heme biosynthesis [17]. This finding is in agreement with study conducted by Kabyemela et al. [18] and Senga et al. [19] who reported a decrease in iron concentration among malaria infected pregnant women.

However, the decreased in iron concentration resulting from malaria pathophysiology is multifaceted. The synthetic role of the liver cannot be discounted as seen by the assault on hepatic cells responsible for the anabolism of iron. Moreover, the oxidative effect of free radicals on red cells is another possible phenomenon that could cascade to the loss of iron. Summarily, it could be inferred that the fall in iron concentration in malaria is both synthetic and oxidative. Hence both could be integrated into holistic therapeutic intervention in malaria treatment and management.

The significant increase in concentrations of oxidative stress indicators could be due to production of free radicals resulting from malaria pathophysiology. Free radicals generations are curtailed by the reciprocal generation of antioxidants. The increase in glutathione concentration could be due to the counteracting effect on free radical generated. Glutathione plays a critical role as a reducing agent and in cellular detoxification [20]. Similarly, the leap observed in malonaldehyde concentration is an indication of oxidative stress [21]. Infected human erythrocytes are under increased oxidative stress exerted by the malaria parasite [22]. This leads to red cell lysis, anaemia and iron concentration fall. This finding agree with a previous study by Idonije et al. [23] who reported a significantly higher concentrations of lipid peroxidation (MDA) in malaria infected patients.

\section{CONCLUSION}

The study revealed significant increase in AST and ALT, malonaldehyde and glutathione levels in malaria infected subjects when compared to the controls. While serum iron decreased. This has brought to bear that oxidative stress and hepatic assault could be indicators of iron deficiency arising from malaria. Hence, biochemical changes observed in this study should be considered in therapeutic intervention of malaria treatment and management.

\section{DISCLOSURE}

The study was sponsored by the authors. No grant or monetary support was gotten from any source.

\section{ACKNOWLEDGMENT}

Special appreciation goes to our project students that aided in the sample collection. Also, a hand of gratitude to the staff of Enis Biomedicals and Forensics (eBf) LTD Igbogene, Bayelsa State, Nigeria for the sample analysis.

\section{REFERENCES}

[1] Breman, J. G. (2001). The ears of the hippopotamus: Manifestations, determinants and estimates of the malaria burden. American Journal of Tropical Medicine Hygiene, 64: 1-11.

[2] Ogbodo, S. O., Okeke, A. C. Obu, H. A., Shu, E. N., and Chukwurah, E. F. (2010). Nutritional status of parasitemic children from malaria endemic rural communities in Eastern Nigeria. Current Pediatric Restriction, 14: 131-135.

[3] Mosab, N. M. H., Huda, B. A., Rofida, A. A., Khadija, E. M., Mozdalifa, B. O., and Fatima, A. S. (2008). Effect of Plasmodium Falciparum and Plasmodium Vivax on Liver Function Mainly Alanine Aminotransferase and Bilirubin among Known Malaria Patient's in River Nile State. Advancements Bioequiv Available, 2(1):2-5.

[4] United Nation International Children Education Fund. (2009) Partnering to roll back malaria in Nigeria's Bauchi State. At a glance: Nigeria. United Nations Children Fund, Abuja, Nigeria.

[5] Enemchukwu, B. N., Ibe, C. C.Udedi, S. C. Iroha, A. Ubaoji, K. I. and Ogundapo S. S. 2014). Liver Function Assessment in Malaria, Typhoid and Malaria-Typhoid Co-Infection in Aba, Abia State, Nigeria. Pakistan Journal of Biological Sciences, 17(6): 860-863.

[6] Erik, R. A and Yatrik, M S. (2013). Iron homeostasis in the liver Compr Physiol., 3(1): 315-330.

[7] Pompella, A., Visvikis, A., Paolicchi, A., De Tata, V., and Casini, A. (2003). The changing faces of glutathione, a cellular protagonist. Biochemical Pharmacology.66(8):1499-1503.

[8] Nair, V., O'Neil, C., and Wang, P. (2008). "Malondialdehyde" Encyclopedia of Reagents for Organic Synthesis.542:78-79.

[9] Davey, M., Stals, E., Panis, B., Keulemans, J., and Swennen, R. (2005). High-throughput determination of malondialdehyde in plant tissues. Analytical Biochemistry.347 (2): 201-207.

[10] Elnoman, A., Elbadawi, N. E., Mohamed, M. I., Elzaki, H., Elimam, N., Ounsa, M. A. A. G., Mohamed, E. Y. (2012). The Effects of Diet and Exercise on Weight-loss - When 2 Plus 2 Could Add Up To 22. Journal of Physiobiochemical Metabolism, 1:2.

[11] Jarike, A. E., Emuveyon, E. E. and Idogun, S. F. (2002). Pitfalls in the interpretation of liver parenchymal and membranous enzyme results. Pre-clinical $P$. falciparum malaria in the Nigerian environment Nigerian Journal of Clinical Medicine, 10: 21-27.

[12] Burtis, C. E., A. Ashwood and B. Border, 2001. Liver Function: Tietz Fundamentals of Clinical Chemistry. 5th Edition. Saunders Company, Philadelphia, Pp: 748-770.

[13] Barry, H. and John. M.C. (2001). Free radicals in Biology and medicine, $3^{\text {rd }}$ edition, oxford science publication, pp 497.

[14] Agoro, E. S., Wankasi, M.M. and Illeimokum, O. (2015) Relationship between Serum Anion Gap and Diabetes Mellitus. Journal of Diabetes Mellitus, 5:199-205.

[15] Mosab, N. M. H., Huda, B. A., Rofida, A. A., Khadija, E. M., Mozdalifa, B. O., and Fatima, A. S. (2008). Effect of Plasmodium Falciparum and Plasmodium Vivax on Liver Function Mainly Alanine Aminotransferase and Bilirubin among Known Malaria Patient's in River Nile State. Advancements Bioequiv Available, 2(1):2-5.

[16] Guthrow, C. E., Morris, J. F., and Day, J. W. (2007). Enhanced noneenzymatic of human serum albumin. Procure National Academic Science United State of America, 76(9): 4258-4261.

[17] Nagaraj V. A., Arumugam R., Gopalakrishnan B., Jyothsna Y. S. Rangarajan P. N., Padmanaban G. (2008). Unique properties of Plasmodium falciparum porphobilinogen deaminase. J. Biol Chem. 283, 437-444.

[18] Kabyemela, E. R., Fried, M., and Kurtis, J. D., Mutabingwa T. K., Duffy P. E. (2008). Decreased susceptibility to Plasmodium 
falciparum infection in pregnant women with iron deficiency. Journal Infectious Diseases, 198: 163-166.

[19] Senga, E. L., Harper, G., Koshy, G., Kazembe, P. N., and Brabin, B. J. (2011). Reduced risk for placental malaria in iron deficient women. Malaria Journal, 10:10-47.

[20] Forman, H., Zhang, H., Rinna, A. (2009). Glutathione: overview of its protective roles, measurement, and biosynthesis. Molcular aspects of medicine, 30(10): 1-12.

[21] Del-Rio, D., Stewart, A., andPellegrini, N. (2005). A review of recent studies on malondialdehyde as toxic molecule and biological marker of oxidative stress. Nutrition Metabolism and Cardiovascular Diseases. 15 (4): 316-328.

[22] Easton, J., Eckman, J., Berger, E. and Jacob, H. (1976). Suppression of malaria infection by oxidant- sensitive host eryhrocytes.Nature.264: 758-760.

[23] Idoniye, O., Festus, O., Okhiai, O. and Akpamu, U. (2011). Comparative Study of the Status of a biomarker of lipid peroxidation (malondialdehyde) in patients with plasmodium falciparum and plasmodium vivax malaria infection. Asian journal of biological sciences.4(6):506-513. 